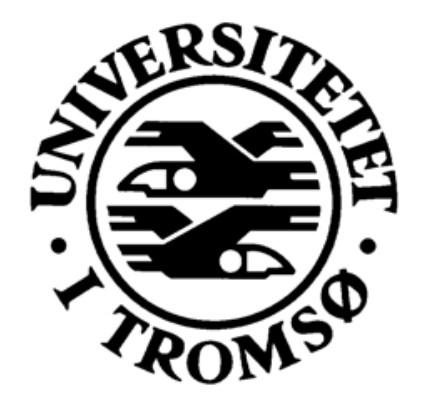

\title{
License Fees: The Case of Norwegian Salmon Farming
}

by

Rolf Färe, Shawna Grosskopf, B.-E. Roland and William L. Weber

Working Paper Series in Economics and Management

No. 07/05, October 2005

Department of Economics and Management

Norwegian College of Fishery Science

University of Tromsø

Norway 
License Fees: The Case of Norwegian Salmon Farming

\author{
Rolf Färe \\ Department of Economics and \\ Department of Agricultural and Resource Economics \\ Oregon State University \\ Corvallis, OR 97331, USA \\ Shawna Grosskopf \\ Department of Economics \\ Oregon State University \\ Corvallis, OR 97331, USA \\ B.-E. Roland \\ University of Tromsø \\ Tromsø, Norway \\ William L. Weber \\ Department of Economics \\ Southeast Missouri State University \\ Cape Girardeau, MO 63701, USA
}




\begin{abstract}
The Norwegian salmon farming industry is one of the most important Norwegian export industries. The industry is also regulated to secure balanced and sustainable development. Current regulatory practice consists of licensing access to sea water. The government recently set an upper bound on the license fees; the purpose of our paper is to estimate the shadow price of the property right to determine whether the current license fee limit is 'too low' as claimed by critics. We model the production process with a directional input distance function; output includes sold salmon as well as the increased biomass of salmon inventory. Inputs include labor, feed, pen capacity, fingerlings, capital, and other variable costs. We estimate a quadratic frontier directional distance function; our mean estimate of the shadow value of the licenses is below the current price ceiling, but has a range such that the upper bound on license fees is binding for some salmon farmers.
\end{abstract}




\section{Introduction}

Salmon farming is one of the most important Norwegian export industries, and Norway is a leading farming country. From a modest start in the 1970’s with many small farms, many mergers have occurred leading to a few large companies. Many of the companies are now listed on the Norwegian stock market. In 2001, Norway supplied $42 \%$ of the total world supply of Atlantic salmon. During 1986 to 2001 the annual production of commercial salmon grew from 54000 metric tons to approximately 440000 metric tons, a 15\% annual growth rate. Fish farming in Norway is by the government expected to be a cornerstone in the Norwegian economy as the oil reserves empties. (SINTEF 2000)

One of the most important and certainly most unique inputs in salmon production is water area. A licensing system controlling access to sea water is the method used to regulate the industry. This practice is regulated by the 1985 Act of June 14 No. 68 which established that no one may own or operate a fish farm without a license. The objective of licensing salmon farmers is to secure a balanced and sustainable development of the fish farming industry. To be granted a license four criteria must be met:

i. the activity contributes to the development of the district and the industry,

ii. the owner must have local connections,

iii. only one person should hold majority interest in one license, and

iv. the fish farmer must hold professional expertise.

Criteria ii. and iii. imply "one owner-one license" with the owner living in the area where he farms. In 1991 the condition "one owner-one license" was removed allowing the possibility of license transfers. This restriction lead to a structural change (Directorate of Fisheries 2000) and subsequent improvements in productivity (see Vassdal and Roland 1998).

The license giving access to water area is not only an important input, but is also the fish farmer's most valuable asset. As long as the right to farm is being executed, it can be considered 
eternal. A license can be transferred to a new owner when a farm is sold. In contrast to agricultural land, the sites for a license can be moved from one sea location to another under certain restrictions. The Ministry of Fisheries that grants new licenses rarely does so. Currently there are a total of about 850 licenses with average volume of 12000 cubic meters of sea area for farming. Due to these factors, the right to operate fish farms tends to be very valuable. Some trading of licenses has occurred and in the year 2000, licenses sold for 30-50 million NOK (4-7 million US dollars). In the deregulation of the fish farming act in June 2002 it was stated that the government would charge a maximum of 5 million NOK (700,000 US dollars) for a new license. Furthermore, new licenses cannot change ownership during the first ten years. Thirtyeight new licenses have been distributed under this new regime.

The Department of Fisheries handles the distribution of rights to farm. In the last two to three years there has been much public debate regarding the distribution of free licenses. The result of the debate has made the authorities decide to distribute future licenses against a charge. However, what the charge should be, is the subject of much debate.

The purpose of this paper is to price licenses using a new shadow-pricing approach based on directional distance functions. Our shadow-pricing technique exploits the duality between the cost function and the directional input distance function. The well-known Pareto efficiency conditions require that the ratio of input prices equal the ratio of their marginal contributions (the marginal rate of substitution) to output. We estimate the directional input distance function to recover the marginal rate of substitution between licenses for ocean space and fish feed. Given the market price of fish feed, our method "reveals" the shadow price of the license. The directional input distance function is employed because it generalizes the technology to the case of multiple outputs and allows a firm to operate at less than 100\% technical efficiency. Depending on the problem at hand, our method can be used to value desirable outputs such as public goods or undesirable outputs like pollution. For example, Färe, Grosskopf, and Weber 
(2001) use a directional output distance function to value the public good characteristics of conservation land produced by the state of Missouri, while Färe, Grosskopf, Noh, and Weber (2004) use a directional output distance function to estimate the shadow cost of sulfur dioxide emitted by electric utilities.

Using our method, we evaluate the input-output data of 170 firms, representing over $60 \%$ of total production in 2000 . In the next section we describe the inputs used by salmon farmers and provide descriptive statistics of the data. Then, in another section, we present the theoretical foundation for our shadow pricing model and our estimation method. A discussion of the empirical results is followed by a summary and conclusion.

\section{Data and Background}

The Norwegian Directorate of Fisheries undertakes an annual survey of the Norwegian fish farming industry. The farms are obliged to report financial and cost accounts as well as answer a questionnaire regarding the license and how it is operated. The data in this study consist of 170 companies representing 505 licenses in the year 2000 . The sample covers $60 \%$ of harvested fish and according to the Directorate of Fisheries, is a representative sample of the industry. $^{1}$

The fish farmer buys smolts (fingerlings) from freshwater hatcheries and grows them to marketable size, which takes $12-18$ months. ${ }^{2}$ The inputs to the production process are license capacity in cubic meters, smolts in NOK, fish feed in Kg, labour hours, capital in NOK, and other various costs in NOK. The use of smolt is only reported in money terms, which is preferred since it reflects differences in the quality and size of the smolt. Other various costs include electricity/energy, administration, repair/maintenance expenses, and leasing costs.

\footnotetext{
${ }^{1}$ Some of the units produce both salmon and trout, but the input usage is not split on the two outputs. However, this can be defended since salmon and trout are only heterogeneous in the market, not in production. The consequence is that one output will yield more revenue than the other, but will not affect our shadow price estimates since we are calculating shadow prices from the input side of the technology.

${ }^{2}$ Farms with a production period not coinciding with the survey period were removed from the data, in our case, two farms.
} 
Capital costs, reflect the value of all production assets, and are reported as estimated depreciation based on the replacement value of assets. The output is the total production of salmon in Kg. The output includes salmon produced for sale and salmon used to increase the biomass.

Table 1 below shows the descriptive statistics.

Table 1. Descriptive Statistics

\begin{tabular}{lrrrr}
\hline K=170 observations & Mean & Std. Dev. & Minimum & Maximum \\
\hline Production $(\mathrm{Kg})$ & $2,096,664.0$ & $2,446,449.0$ & 374,197 & $14,451,821$ \\
Used capacity $\left(\mathrm{m}^{3}\right)$ & $55,257.0$ & $72,359.0$ & 8,300 & 605,282 \\
Smolt cost $(\mathrm{NOK})$ & $5,116,146.1$ & $6,130,585.1$ & 42,7500 & $3,483,7000$ \\
Feed $(\mathrm{Kg})$ & $25,468,720$ & $3,053,748.8$ & $40,5470.0$ & $17,121,925$ \\
Labour hours & $13,273.4$ & $13,857.9$ & 1,875 & 73,125 \\
Capital (NOK) & $1,559,971.5$ & $2,164,901.3$ & 39,102 & $12,586,485$ \\
Various costs (NOK) & $5,998,286.3$ & $10,384,596.6$ & 180,189 & $105,991,458$ \\
Price of feed (NOK) & 6.6 & 0.7 & 4 & 9 \\
\hline
\end{tabular}

The production of salmon takes place in the sea. Producers buy smolt/fingerlings from freshwater hatcheries, and feed the fish up to marketable size. The routine of the fish farm is designed to maintain the well-being of the fish, to promote efficient growth and to minimize the stress, which increase the susceptibility of the salmon to disease and injury. Production is restricted by physical capacity as well as inputs that can be bought freely in the market. ${ }^{3}$ Fish are fed pellets consisting of fish meal and fish oil which are partially derived from wild salmon. An important role for labour is to monitor the feed as it drifts through the pens and to cease feeding once too many pellets drift to the bottom rather than being eaten by the fish. Innovations in feed pellets, including pellets that sink more slowly through the pen and the use of pellets which substitute vegetable oil for fish oil have improved fish farm efficiency and promoted sustainability of wild salmon stocks. (Asche, Guttormsen and Tveterås 1999) Moreover, while the use of feed can lead to eutrophication or algal blooms in coastal waters, this potential

\footnotetext{
${ }^{3}$ Feed quotas attached to each license were introduced in 1996 to slow down the rapid growth in production and this system is still in place.
} 
external cost has been mitigated by moving fish farms from areas with low water exchange to areas with high flushing capacity. In addition, while fish are given antibiotics through feed to prevent disease causing a potential external cost, a change from curative (antibiotics) to preventive disease treatment (an oil vaccine given to salmon before they enter the sea pens) in the 1990s has reduced the use of antibiotics dramatically, while fish production has increased. (Asche, Guttormsen and Tveterås 1999)

\section{Method}

We wish to derive the shadow price for a commercial salmon fishing license and yet allow for the possibility that commercial salmon farmers might be inefficient producers. We base our model on the directional input distance function (Chambers, Chung, and Färe 1996) which was introduced in consumer theory by Luenberger (1992) as the benefit function. We denote inputs by $x \in R_{+}^{N}$ and outputs by $y \in R_{+}^{M}$. The technology is represented by the input requirement sets $L(y), y \in R_{+}^{M}$, where

$L(y)=\{x: x$ can produce $y\}$.

We assume that $\mathrm{L}(\mathrm{y})$ meets the standard production assumptions including; it is a closed, convex set with inputs and outputs freely disposable and no free lunch.

Let $g \in R_{+}^{N}, \quad g \neq 0$ be a directional vector. Then the directional input distance function is defined as

$\vec{D}_{I}(y, x ; g)=\max \{\beta:(x-\beta g) \in L(y)\}$.

This function inherits the properties of the input sets and is a complete characterization of the technology in the sense of

$L(y)=\left\{x: \vec{D}_{I}(y, x ; g) \geq 0\right\}$. 
When used as an efficiency indicator, an observation $\left(x^{k}, y^{k}\right)$ is termed efficient if $\vec{D}_{I}(y, x ; g)=0$ and is inefficient if $\vec{D}_{I}(y, x ; g)>0$. From its definition, the directional input distance function acquires the translation property, i.e.,

$\vec{D}_{I}(y, x+\alpha g ; g)=\vec{D}_{I}(y, x ; g)+\alpha$.

The translation property is related to the homogeneity property of the Shephard (1970) input distance function defined as:

$D_{i}(y, x)=\max \{\lambda:(x / \lambda) \in L(y)\}$.

When one chooses a directional vector, $g=x$, the directional input distance function can be recovered from the input distance function as:

$\vec{D}_{I}(y, x ; g)=1-\frac{1}{D_{i}(y, x)}$

We are interested in deriving shadow prices of inputs for which market prices do not exist. Let $w \in R_{+}^{N}$ denote the vector of input prices. The cost function is defined as:

$C(y, w)=\min _{x}\{w x: x \in L(y)\}=\min _{x}\left\{w x: \vec{D}_{I}(y, x ; g) \geq 0\right\}$

By definition we know that if $x \in L(y)$, then $\left(x-\vec{D}_{I}(y, x ; g) \cdot g\right) \in L(y)$. Therefore, $C(y, w) \leq w\left(x-\vec{D}_{I}(y, x ; g) \cdot g\right)=w x-w g \vec{D}_{I}(y, x ; g)$

Equation (8) states that minimum costs are no greater than actual costs, $w x$, less the cost reduction due to the elimination of any technical inefficiency, $w g \vec{D}_{I}(y, x ; g)$. By rearranging (8), we may recover the directional input distance function from the cost function by:

$\vec{D}_{I}(y, x ; g)=\min _{w}\left\{\frac{w x-C(y, w)}{w g}\right\}$.

Applying the envelope theorem to (9) yields the normalized shadow price vector:

$\nabla_{x} \vec{D}_{I}(y, x ; g)=\frac{w}{w g} \geq 0$ 
Assume that the price of input $\mathrm{j}, w_{j}$, is a market price. In our example, we use the price of feed.

Then the absolute shadow price of input i can be computed as:

$w_{i}=w_{j}\left(\frac{\partial \vec{D}_{I}(y, x ; g) / \partial x_{i}}{\partial \vec{D}_{I}(y, x ; g) / \partial x_{j}}\right)$.

We use (11) as our basis for deriving the shadow price of a commercial salmon license.

\section{Empirical Specification}

Following Chambers (1998) we specify and estimate a quadratic form for the directional input distance function and use the estimates to derive shadow price estimates for commercial fishing licenses using (11). We choose a quadratic form for the directional input distance function because it serves as a second-order approximation to a true, but unknown function, while allowing us to impose the translation property specified in (4). We choose the directional vector, $g=1$, so that the estimate of inefficiency is the unit contraction in inputs that can still produce the output vector $y$.

The quadratic directional input distance function takes the form:

$$
\vec{D}_{I}(y, x ; 1)=\alpha_{0}+\sum_{n=1}^{N} \alpha_{n} x_{n}+\frac{1}{2} \sum_{n=1}^{N} \sum_{n^{\prime}=1}^{N} \alpha_{n n} x_{n} x_{n^{\prime}}+\sum_{m=1}^{M} \beta_{m} y_{m}+\frac{1}{2} \sum_{m=1}^{M} \sum_{m^{\prime}=1}^{M} \beta_{m m^{\prime}} y_{m} y_{m^{\prime}}+\sum_{n=1}^{N} \sum_{m=1}^{M} \delta_{n m} x_{n} y_{m}
$$

where we impose symmetry, $\alpha_{n n^{\prime}}=\alpha_{n^{\prime} n}, n \neq n^{\prime}, \beta_{m m^{\prime}}=\beta_{m^{\prime} m}, m \neq m^{\prime}$. The translation property given in (4) requires the further restrictions that $\sum_{n=1}^{N} \alpha_{n}=1, \sum_{n^{\prime}=1}^{N} \alpha_{n n^{\prime}}=\sum_{m=1}^{M} \delta_{n m}=0, n=1, \ldots, N$. We also impose monotonicity conditions, $\frac{\partial \vec{D}_{I}(y, b ; 1)}{\partial x_{n}}=\alpha_{n}+\sum_{n^{\prime}=1}^{N} \alpha_{n n^{\prime}} x_{n^{\prime}}+\sum_{m=1}^{M} \delta_{n m} y_{m} \geq 0, n=1, \ldots, N$ and $\frac{\partial \vec{D}_{I}(y, b ; 1)}{\partial y_{m}}=\beta_{m}+\sum_{m^{\prime}=1}^{M} \beta_{m m^{\prime}} y_{m^{\prime}}+\sum_{n=1}^{N} \delta_{n m} x_{n} \leq 0, m=1, \ldots, M$. We follow the work of Aigner and Chu (1968) and estimate the parameters of (11) in deterministic form. Assuming that there 
are $\mathrm{k}=1, \ldots, \mathrm{K}$ firms we choose the parameter $\alpha_{o}, \alpha_{n n^{\prime}}, \beta_{m}$ and $\beta_{m m^{\prime}}$, by solving the minimization problem:

$\min \sum_{k=1}^{K}\left\{\vec{D}_{I}\left(y^{k}, x^{k} ; 1\right)-0\right\} \quad$ subject to

i) $\vec{D}_{I}\left(y^{k}, x^{k} ; 1\right) \geq 0, k=1, \ldots, K$,

ii) $\frac{\partial \vec{D}_{I}\left(y^{k}, x^{k} ; 1\right)}{\partial x_{n}} \geq 0, n=1, \ldots, N, \quad k=1, \ldots, K$

iii) $\frac{\partial \vec{D}_{I}\left(y^{k}, x^{k} ; 1\right)}{\partial y_{m}} \leq 0, m=1, \ldots, M, \quad k=1, \ldots, K$

iv) $\alpha_{n n^{\prime}}=\alpha_{n^{\prime} n}, n \neq n^{\prime}, \beta_{m m^{\prime}}=\beta_{m^{\prime} m}, m \neq m^{\prime}$

iv) $\sum_{n=1}^{N} \alpha_{n}=1, \sum_{n^{\prime}=1}^{N} \alpha_{n n^{\prime}}=\sum_{m=1}^{M} \delta_{n m}=0, n=1, \ldots, N$.

The deterministic approach chooses the parameters that minimize the distance of each firm's input combination to the frontier isoquant that can produce the output vector. The restrictions in (13 i-v) impose feasibility, monotonicity, symmetry, and the translation property. Given the parameter estimates of the directional input distance function and the market price of input $j$, the shadow price of input $i$ is:

$$
w_{i}=w_{j}\left(\frac{\alpha_{i}+\sum_{n^{\prime}=1}^{N} \alpha_{i n^{\prime}} x_{n^{\prime}}+\sum_{m=1}^{M} \delta_{i m} y_{m}}{\alpha_{j}+\sum_{n^{\prime}=1}^{N} \alpha_{j n^{\prime}} x_{n^{\prime}}+\sum_{m=1}^{M} \delta_{j m} y_{m}}\right) .
$$

\section{Empirical Results}

Kilograms of salmon $\left(\mathrm{y}_{1}\right)$ are produced from six inputs $\mathrm{x}=\left(\mathrm{x}_{1}, \ldots, \mathrm{x}_{6}\right)=($ ocean pen space, smolt, feed, capital, various other costs, labour). Ocean pen space is measured in cubic meters, fish feed in kilograms, and labour in hours. Smolt, capital, and various costs are measured in Norwegian kroner. Because of the numerical size of our inputs and outputs and to avoid convergence problems when estimating (13) we divided production ( $\left.\mathrm{y}_{1}\right)$ by 10,000,000, and 
scaled the input vector $\mathrm{x}=\left(\mathrm{x}_{1}, \ldots, \mathrm{x}_{6}\right)$ by dividing by $(10000,1000000,1000000,1000,1000000$, 1000000). Scaling the inputs in this manner requires us to interpret the estimate of inefficiency given by the directional input distance function as the number of units times the scaling vector that could be reduced if the firm were to become more efficient. We use the price of fish feed as our market price and estimate the marginal rate of substitution between licenses and fish feed to estimate the shadow price of a license. Given our input scaling vector, we must factor the estimate of the shadow price of a cubic meter of ocean pen space in terms of the value of fish feed by $100=(1000000 / 10000)$.

The parameter estimates of the quadratic distance function are given in Table 2. The estimate of inefficiency and the shadow price per cubic meter of ocean pen space are given in Table 3. The mean value of inefficiency is $\vec{D}_{I}(y, x ; 1)=0.64$ and ranges between 0 and 5.79. Given the scaling vector for inputs, the mean estimate of inefficiency implies that if a fish farmer operated efficiently, it could produce its output using 6400 fewer cubic meters of ocean space, spend 640,000 Kr less on smolts/fingerlings, use 640,000 kg less in fish feed, use 640 fewer labour hours, and spend 640,000 Kr less on capital and 640,000 Kr less in other variable input costs. Eight fish farmers had zero inefficiency and operated on the frontier of $L(y)$. In Figure 1 we graph the kernel distribution of inefficiency assuming a standard normal kernel. Pagan and Ullah (1999) provide details on kernel distributions.

The mean price of fish feed is $6.6 \mathrm{Kr} / \mathrm{kg}$ and ranges between $4 \mathrm{Kr}$ and $9 \mathrm{Kr}$. Using equation (14) for ocean pen space $\left(\mathrm{x}_{1}\right)$ and fish feed $\left(\mathrm{x}_{3}\right)$ yielded a shadow price estimate of 4.06/Kr per cubic meter. The shadow price ranges from 0 to $91.85 \mathrm{Kr}$ per cubic meter. We graph the kernel distribution of shadow prices per cubic meter in Figure 2. A purchased license assigns a property right to ocean space for the fish farmer. Licenses typically are purchased in units of 12,000 cubic meters. To the extent that the license is a right to ocean space in perpetuity we must discount the future stream of income resulting from the license to get the 
estimated value of the license. Values for a 12,000 cubic meter license in perpetuity are presented in Table 3 for discount rates between 3\% and 15\%. The estimates of the shadow value of the license range from 1.6 million $\mathrm{Kr}$ for a discount rate of $\mathrm{R}=3 \%$ to 324 thousand $\mathrm{Kr}$ for a discount rate of $\mathrm{R}=15 \%$. For our range of discount rates, the maximum shadow value is in excess of the 5 million Kr price ceiling assigned by Norway. However, higher discount rates, reflecting greater risk or uncertainty about whether the farmer would receive the property right in perpetuity, would yield estimates below the price ceiling. In contrast, higher fish feed prices would yield higher shadow prices for ocean pen space.

For comparison purposes we also estimate the shadow price of ocean pen space using a CES production function. A description of the CES production function, derived shadow price, and coefficient estimates are given in the Appendix. Because of convergence problems in the nonlinear estimation of the CES production function we were forced to impose constant returns to scale on the estimates. In addition, our production function estimates do not account for any potential inefficiency on the part of salmon farmers. As with the directional input distance function estimates we use the feed price and feed input to estimate the shadow price of a cubic meter of ocean pen space. The parameter estimates of the CES production function yield a mean shadow price of $29.2 \mathrm{Kr}$ per cubic meter (s=26.76) and a range between $3.5 \mathrm{Kr}$ to 257.6 Kr per cubic meter of ocean space. Recall that the price ceiling for 12000 cubic meters of ocean pen space for new licensees is 5 million $\mathrm{Kr}$. Given the mean estimate of the shadow price, a 7\% discount rate would yield a 5 million Kr price for 12000 cubic meters of ocean pen space. Discount rates less than 7\% would cause the price ceiling to be exceeded given the mean shadow price estimate of ocean pen space. Clearly these estimates are higher than those estimates derived from the directional input distance function. This finding suggests the need for researchers to carefully consider the functional form and estimation procedure they use in deriving estimates of shadow prices. We prefer the directional input distance function estimates 
for several reasons. First, the quadratic functional form we employ serves as a second-order approximation to a true, but unknown distance function that defines the relevant salmon production technology. Second, our estimation procedure does not require us to impose an ad hoc error structure or to impose a given functional form (CES) on the production function. Third, our estimates allow for the possibility that salmon farmers are inefficient in their use of inputs. That is, our procedure gives the best-practice technology from the set of all observed fish-farmer practices, rather than an average ad hoc technology.

Returning to the directional input distance function estimates we further examine the distribution of shadow prices by comparing the shadow price of a cubic meter of ocean pen space for the eight firms that operated on the frontier of L(y) and for the 162 firms that exhibited some degree of inefficiency. For the eight firms on the frontier the shadow price per cubic meter was $21.3 \mathrm{Kr}$ while for the 162 firms that were inefficient, the shadow price was $3.2 \mathrm{Kr}$. There are two reasons why these prices might be so different. The first reason might be that the price of fish feed differs for firms on the frontier versus inefficient firms. Efficient fish farmers did face a slightly higher price, $6.74 \mathrm{Kr} / \mathrm{kg}$ of feed, versus $6.58 \mathrm{Kr} / \mathrm{kg}$ of feed for inefficient farmers, but the difference was insignificant based on a t-test.

A second reason for the difference in shadow prices for the frontier firms and the inefficient firms could be due to the directional vector chosen to evaluate the distance function. For those firms which are efficient, changing the directional vector should not change the marginal rate of substitution between inputs and consequently, the shadow price should not change. However, for those firms which are inefficient, the choice of the directional vector will determine the point on the isoquant of $\mathrm{L}(\mathrm{y})$ to which the firm is evaluated. Figure 3 illustrates the potential for this kind of phenomenon. The input requirement set is given as $\mathrm{L}(\mathrm{y})$ for two firms. One firm operates on the frontier at $\mathrm{A}$, while the other firm is inefficient and is represented by point $B$. Given a directional vector $g=(1,1)$, the shadow price of a license for 
firm B is evaluated at point C. Clearly a different choice of directional vector, such as g', would change the point on the frontier to which firm B is evaluated, but would not change the shadow price for firm A.

\section{Conclusion}

Commercial salmon fishing is a major export industry in Norway. One of the critical inputs in the production of commercial salmon is ocean pen space. After 1985, all commercial salmon fishers must secure a license for ocean pen space from the Norwegian Ministry of Fisheries. The licenses establish a property right to the ocean, which can be traded after ten years from the initial issuance, but with a price ceiling of five million Kr per 12000 cubic meters. Given that licenses are an important, but un-priced input in the production process, we provide a method to determine the shadow price of a license. Our method exploits the duality between the directional input distance function, which is a complete representation of the firm's technology, and the firm's minimum cost function. We implement our method using a quadratic specification of the distance function estimated using a deterministic frontier method. Our findings indicate that a cubic meter of ocean space is worth around $4 \mathrm{Kr}$, with a range between 0 and 91. Given plausible discount rates, our estimates suggest that the price ceiling will be binding for some for some commercial salmon farmers. 
Table 2. Quadratic Directional Input Distance Function Estimates

$\mathrm{x}_{1}=$ license size $\left(\mathrm{m}^{3}\right), \mathrm{x}_{2}=\operatorname{smolt}(\mathrm{kr}), \mathrm{x}_{3}=$ fish feed $(\mathrm{kg}), \mathrm{x}_{4}=$ capital cost $(\mathrm{kr})$,

$\mathrm{x}_{5}=$ various other costs $(\mathrm{kr}), \mathrm{x}_{6}=$ labour hours

\begin{tabular}{|c|c|c|}
\hline Coefficient & Variable & Estimate \\
\hline$\alpha_{0}$ & Constant & 0.4129 \\
\hline$\alpha_{1}$ & $\mathrm{X}_{1}$ & 0.0006 \\
\hline$\alpha_{2}$ & $\mathrm{X}_{2}$ & -0.0027 \\
\hline$\alpha_{3}$ & $\mathrm{X}_{3}$ & 0.6884 \\
\hline$\alpha_{4}$ & $\mathrm{X}_{4}$ & 0.0002 \\
\hline$\alpha_{5}$ & $\mathrm{X}_{5}$ & 0.2839 \\
\hline$\alpha_{6}$ & $\mathrm{X}_{6}$ & 0.0297 \\
\hline$\alpha_{11}$ & $\mathrm{X}_{1} \mathrm{X}_{1}$ & -0.0003 \\
\hline$\alpha_{12}$ & $\mathrm{X}_{1} \mathrm{X}_{2}$ & -0.0005 \\
\hline$\alpha_{13}$ & $\mathrm{X}_{1} \mathrm{X}_{3}$ & 0.0008 \\
\hline$\alpha_{14}$ & $\mathrm{X}_{1} \mathrm{X}_{4}$ & 0.0002 \\
\hline$\alpha_{15}$ & $\mathrm{X}_{1} \mathrm{X}_{5}$ & -0.0001 \\
\hline$\alpha_{16}$ & $\mathrm{X}_{1} \mathrm{X}_{6}$ & -0.0001 \\
\hline$\alpha_{22}$ & $\mathrm{X}_{2} \mathrm{X}_{2}$ & -0.0060 \\
\hline$\alpha_{23}$ & $\mathrm{X}_{2} \mathrm{X}_{3}$ & 0.0073 \\
\hline$\alpha_{24}$ & $\mathrm{X}_{2} \mathrm{X}_{4}$ & -0.0001 \\
\hline$\alpha_{25}$ & $\mathrm{X}_{2} \mathrm{X}_{5}$ & -0.0016 \\
\hline$\alpha_{26}$ & $\mathrm{X}_{2} \mathrm{X}_{6}$ & 0.0008 \\
\hline$\alpha_{33}$ & $\mathrm{X}_{3} \mathrm{X}_{3}$ & -0.0533 \\
\hline$\alpha_{34}$ & $\mathrm{X}_{3} \mathrm{X}_{4}$ & 0.0000 \\
\hline$\alpha_{35}$ & $\mathrm{X}_{3} \mathrm{X}_{5}$ & 0.0461 \\
\hline$\alpha_{36}$ & $\mathrm{X}_{3} \mathrm{X}_{5}$ & -0.0009 \\
\hline$\alpha_{44}$ & $\mathrm{X}_{4} \mathrm{X}_{4}$ & 0.0000 \\
\hline$\alpha_{45}$ & $\mathrm{X}_{4} \mathrm{X}_{5}$ & -0.0001 \\
\hline$\alpha_{46}$ & $\mathrm{X}_{4} \mathrm{X}_{6}$ & 0.0000 \\
\hline$\alpha_{55}$ & $\mathrm{X}_{5} \mathrm{X}_{5}$ & -0.0001 \\
\hline$\alpha_{56}$ & $\mathrm{X}_{5} \mathrm{X}_{6}$ & -0.0445 \\
\hline$\alpha_{66}$ & $\mathrm{X}_{6} \mathrm{X}_{6}$ & 0.0000 \\
\hline$\beta_{1}$ & $\mathrm{Y}_{1}$ & -9.5714 \\
\hline$\beta_{11}$ & $\mathrm{Y}_{1} \mathrm{Y}_{1}$ & -9.7000 \\
\hline$\delta_{11}$ & $\mathrm{X}_{1} \mathrm{Y}_{1}$ & 0.0149 \\
\hline$\delta_{21}$ & $\mathrm{X}_{2} \mathrm{Y}_{1}$ & 0.3154 \\
\hline$\delta_{31}$ & $\mathrm{X}_{3} \mathrm{Y}_{1}$ & -0.0079 \\
\hline$\delta_{41}$ & $\mathrm{X}_{4} \mathrm{Y}_{1}$ & 0.0023 \\
\hline$\delta_{51}$ & $\mathrm{X}_{5} \mathrm{Y}_{1}$ & -0.2956 \\
\hline$\delta_{61}$ & $\mathrm{X}_{6} \mathrm{Y}_{1}$ & -0.0291 \\
\hline
\end{tabular}


Table 3-Shadow prices and inefficiency

\begin{tabular}{|c|c|c|c|c|c|}
\hline & & Mean & Std. Dev. & Minimum & Maximum \\
\hline \multicolumn{2}{|l|}{$\vec{D}_{I}(y, x ; 1)$} & 0.64 & 0.56 & 0 & 5.79 \\
\hline \multicolumn{2}{|c|}{ Shadow price of a license } & 4.06 & 7.78 & 0 & 91.85 \\
\hline \multicolumn{6}{|c|}{ Discount rate } \\
\hline $\begin{array}{l}\text { License for } \\
12,000^{3} \mathrm{~m}(\mathrm{NOK})\end{array}$ & $\begin{array}{l}\mathrm{R}=.03 \\
\mathrm{R}=.05 \\
\mathrm{R}=.07 \\
\mathrm{R}=.09 \\
\mathrm{R}=.11 \\
\mathrm{R}=.13 \\
\mathrm{R}=.15\end{array}$ & $\begin{array}{r}1,624,093.0 \\
974,455.8 \\
696,039.8 \\
541,364.3 \\
442,934.4 \\
374,790.7 \\
324,818.6\end{array}$ & $\begin{array}{r}3,148,322 \\
1,888,993 \\
1,349,281 \\
1,049,441 \\
858,633 \\
726,536 \\
629,664\end{array}$ & $\begin{array}{l}0 \\
0 \\
0 \\
0 \\
0 \\
0 \\
0\end{array}$ & $\begin{array}{r}36,741,712 \\
22,045,027 \\
15,746,448 \\
12,247,237 \\
10,020,467 \\
8,478,857 \\
7,348,342\end{array}$ \\
\hline
\end{tabular}


Figure 1-Kernel Distribution of Inefficiency

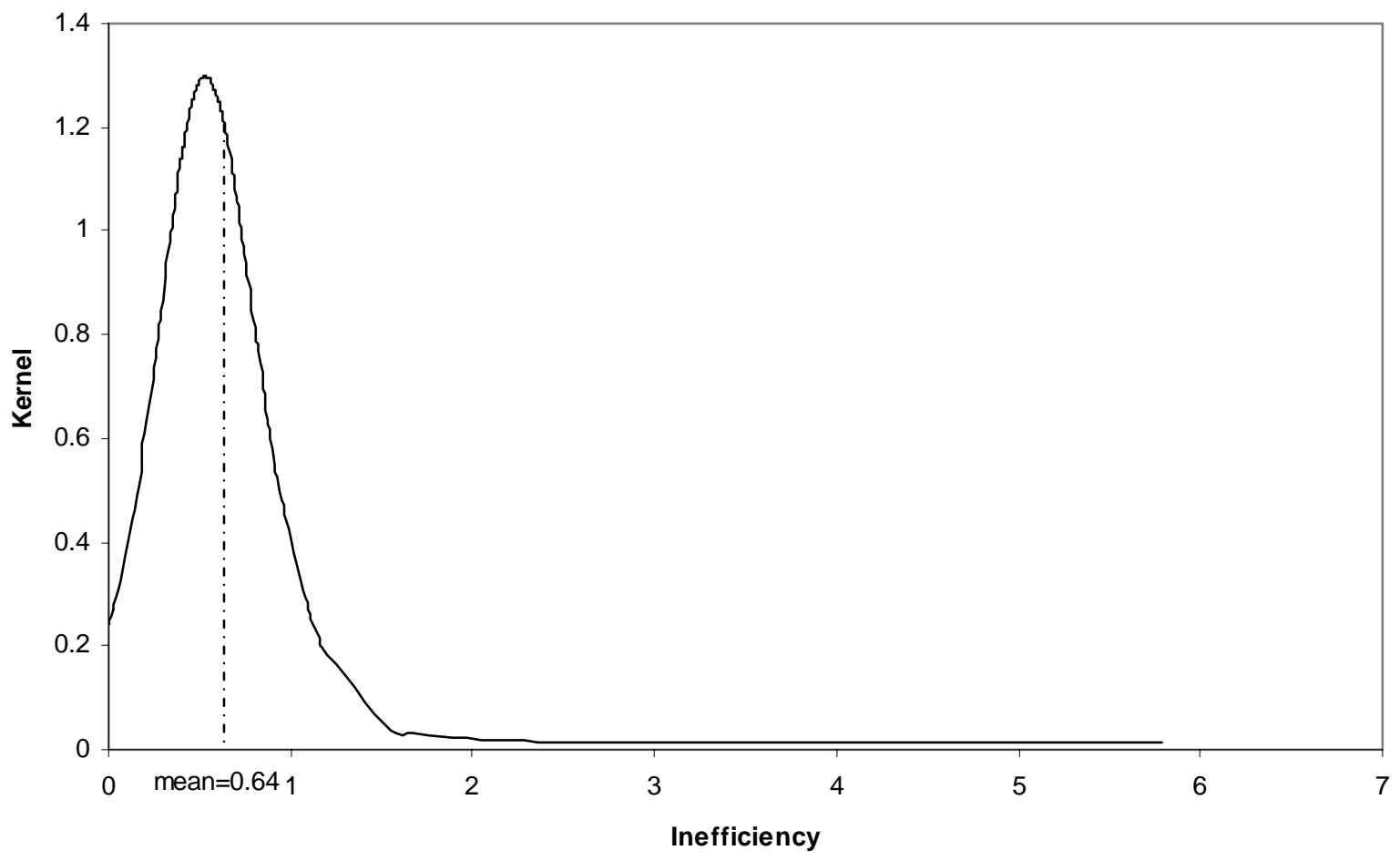


Figure 2-Kernel Distribution of Shadow Prices of a License

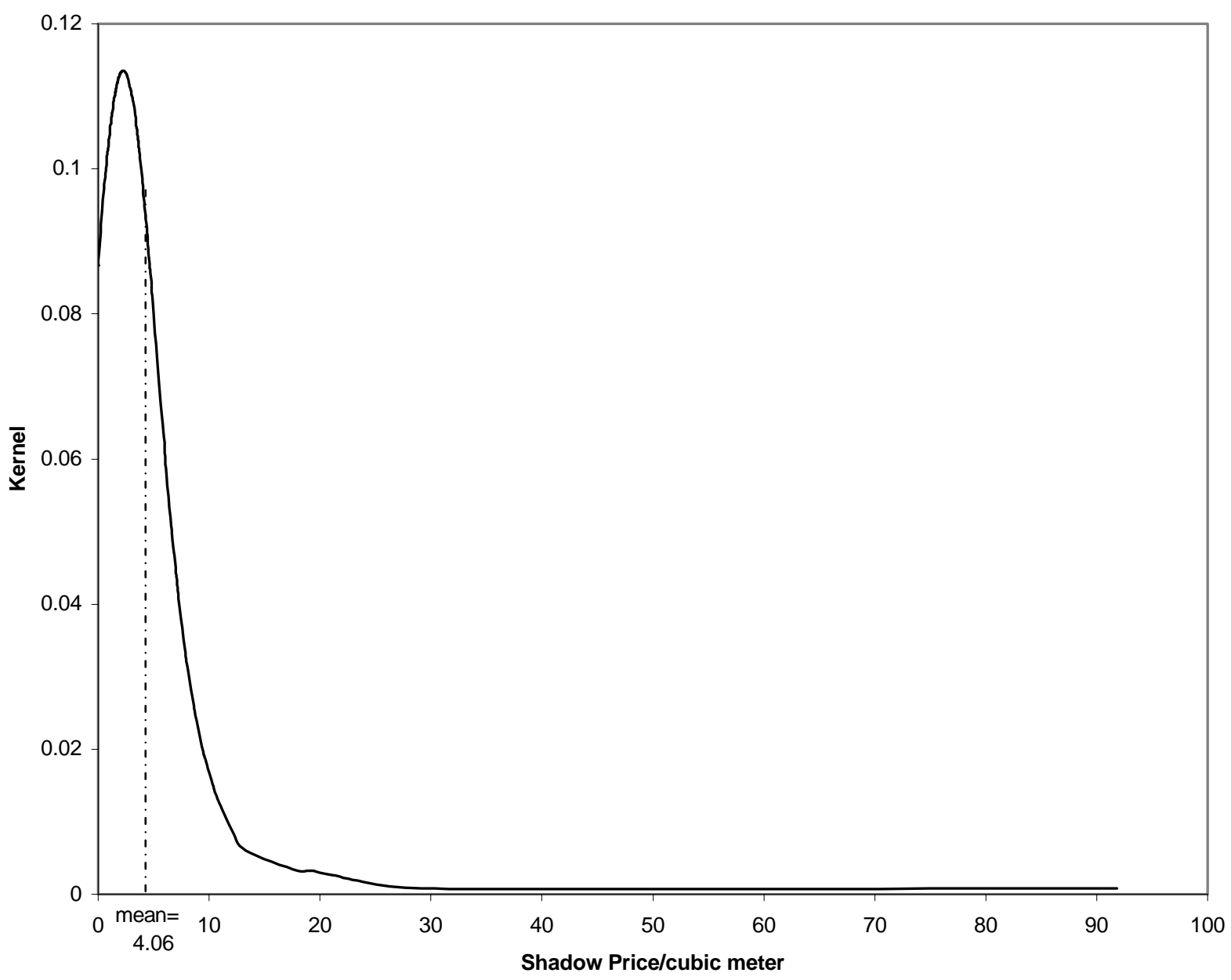


Figure 3-Shadow Prices of Efficient and Inefficient Firms

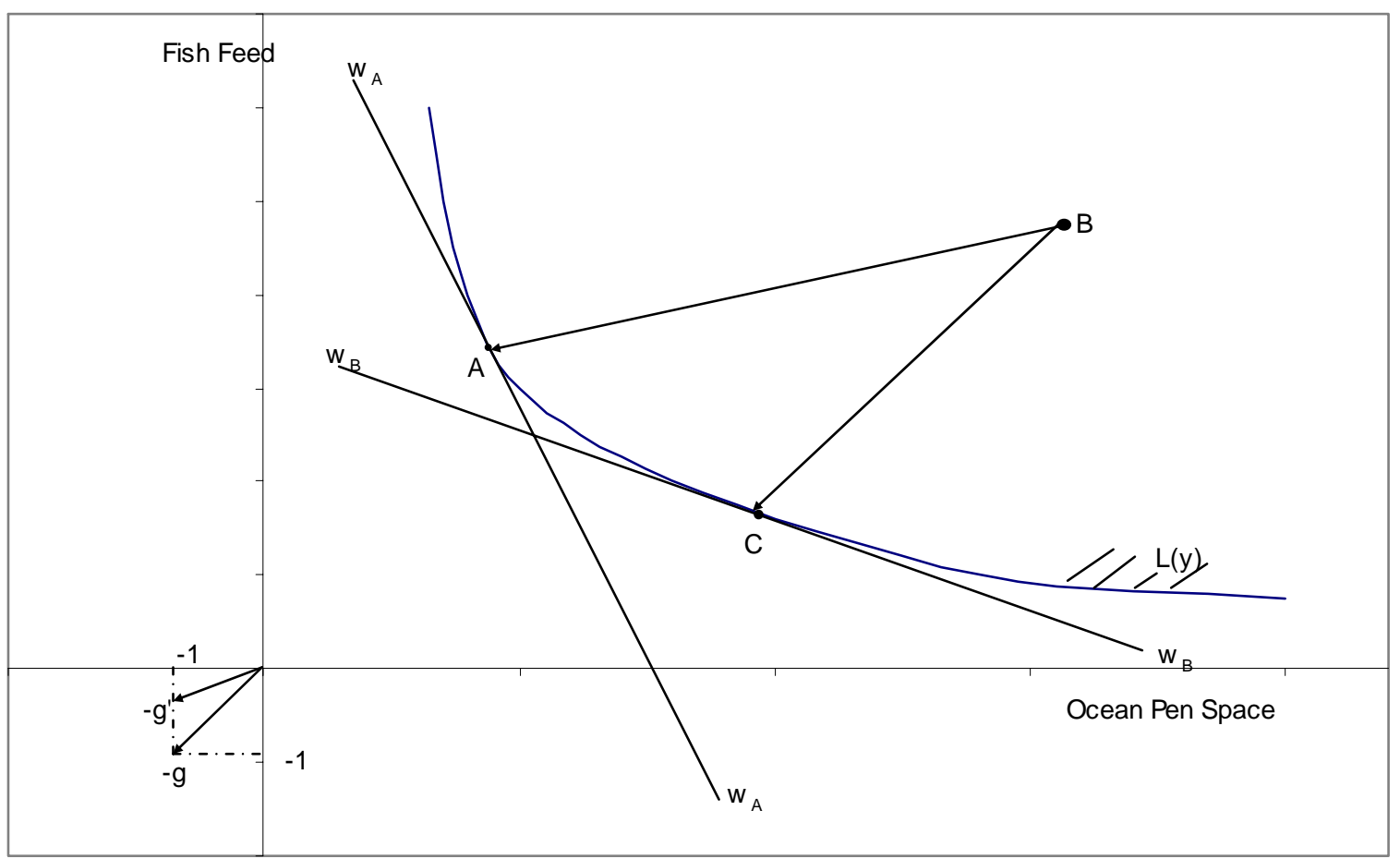




\section{References}

Aigner, D. and C. F. Chu. 1968. "On Estimating the Industry Production Function." American Economic Review, 58:4, 826-839.

Asche, F., A. G. Guttormsen, and R. Tveterås. 1999. "Environmental Problems, Productivity and Innovations in Norwegian Salmon Aquaculture," Aquaculture Economics and Management, 3(1), 19-29.

Chambers, R. G., Y. Chung and R. Färe. 1996. "Benefit and Distance Functions." Journal of Economic Theory. 70:2, 407-419.

Chambers, R. G. 1998. "Input and Output Indicators," in Färe, R., Grosskopf, S., and Russell, R. R. eds., Index Numbers: Essays in Honour of Sten Malmquist, Kluwer Academic Publishers, Boston.

Färe, R., S. Grosskopf, and W. L. Weber. 2001. "Shadow Prices of Missouri Public Conservation Land," Public Finance Review, 29(6), 444-460.

Färe, R., S. Grosskopf, D-W Noh, and W. L. Weber. 2004. "Characteristics of a Polluting Technology: Theory and Practice," forthcoming in Journal of Econometrics.

Luenberger, D.G. 1992. "Benefit Functions and Duality." Journal of Optimization Theory and Applications. 75, 221-264.

Pagan, A. and A. Ullah. 1999. Nonparametric Econometrics. Cambridge: Cambridge University Press.

Shephard, R. W. 1970. Theory of Cost and Production Functions. Princeton: Princeton University Press.

SINTEF 2000. Potensialet for havbruk som en vesentlig basinsnæring i Norge. Report no. STF38 A00611. Trondheim city: SINTEF.

Vassdal, Terje and B.E. Roland. 1998. "Technical Change in the Norwegian Salmon Aquaculture Sector: A Malmquist Index Approach." Paper presented at IIFET'98 Conference in Tromsø, July (15 pages).

The Directorate of Fisheries 2000. Lønnsomhetsundersøkelsen for matfiskanlegg, Bergen city: The Directorate of Fisheries. (Profitability survey for sea water fish farms) 


\section{Appendix}

We also estimate the shadow price of a license using a constant elasticity of substitution (CES) production function which takes the form: $y=A\left[\sum_{n=1}^{N} \delta_{n} x_{n}^{-\rho}\right]^{-1 / \rho}$, $\delta_{n} \geq 0, n=1, \ldots, N, \sum_{n} \delta_{n}=1,-1<\rho<\infty$. For the CES production function the marginal product of each input is $\frac{\partial y}{\partial x_{n}}=\frac{\delta_{n}}{A^{\rho}}\left(\frac{y}{x_{n}}\right)^{\rho+1}, \mathrm{n}=1, \ldots, \mathrm{N}$ which yields the shadow price of the $\mathrm{n}^{\text {th }}$ input $\left(w_{n}\right)$ in terms of the $\mathrm{j}^{\text {th }}$ input price equal to $w_{n}=w_{j}\left(\frac{\delta_{n}}{\delta_{j}}\right)\left(\frac{x_{j}}{x_{n}}\right)^{1+\rho}$. The parameter estimates are:

\begin{tabular}{lcccccccc}
\hline & $\mathrm{A}$ & $\delta_{1}$ & $\delta_{2}$ & $\delta_{3}$ & $\delta_{4}$ & $\delta_{5}$ & $\delta_{6}$ & $\rho$ \\
\hline Estimate & $0.053^{*}$ & $0.049^{*}$ & $0.123^{*}$ & $0.463^{*}$ & $0.216^{*}$ & 0.004 & 0.145 & $0.606^{*}$ \\
(Std. Error) & $(0.004)$ & $(0.018)$ & $(0.035)$ & $(0.067)$ & $(0.082)$ & $(0.007)$ &. & $(0.261)$ \\
\hline
\end{tabular}

*indicates coefficient is significant at the $\alpha=0.05$ level. 